OPEN ACCESS

Edited by:

Hongbo Pan,

Shanghai Ocean University, China

Reviewed by:

Pierangelo Luporini,

University of Camerino, Italy

Xumiao Chen

Institute of Oceanology (CAS), China

${ }^{*}$ Correspondence:

Feng Gao

gaof@ouc.edu.cn

${ }^{\dagger}$ These authors have contributed equally to this work

Specialty section:

This article was submitted to

Marine Evolutionary Biology,

Biogeography and Species Diversity,

a section of the journal

Frontiers in Marine Science

Received: 09 October 2020 Accepted: 07 December 2020

Published: 05 January 2021

Citation:

Asghar U, Chi Y, Gao Y, Lu B,

Jiang $Y$, Gong $R, M a H$,

Al-Rasheid KAS and Gao F (2021)

Morphogenesis of the Ciliature During

Sexual Process of Conjugation

in the Ciliated Protist Euplotes raikovi.

Front. Mar. Sci. 7:615377.

doi: 10.3389/fmars.2020.615377

\section{Morphogenesis of the Ciliature During Sexual Process of Conjugation in the Ciliated Protist Euplotes raikovi}

\author{
Usman Asghar ${ }^{1,2 t}$, Yong Chi, ${ }^{1,2}$, Yunyi Gao ${ }^{1,2}$, Borong Lu ${ }^{1,2}$, Yaohan Jiang ${ }^{1,2}$, \\ Ruitao Gong 1,2, Honggang Ma1,2, Khaled A. S. Al-Rasheid ${ }^{3}$ and Feng Gao ${ }^{1,2 *}$ \\ ${ }^{1}$ Institute of Evolution and Marine Biodiversity, Ocean University of China, Qingdao, China, ${ }^{2}$ Key Laboratory of Mariculture \\ (Ocean University of China), Ministry of Education, Qingdao, China, ${ }^{3}$ Zoology Department, College of Sciences, King Saud \\ University, Riyadh, Saudi Arabia
}

Morphogenesis is an important process that widely occurs in almost all the organisms, including the ciliated protists. Ciliates are a large group of single-celled eukaryotes that can reproduce asexually (e.g., binary fission) and perform sexual process (e.g., conjugation). Morphogenesis happens in both asexual reproduction and sexual process in ciliates and the reorganization during conjugation is more complex. However, studies of morphogenesis focusing on conjugation are very limited. Here we studied the morphogenetic process during conjugation in the marine species Euplotes raikovi Agamaliev, 1966. The results indicate that: (1) the ciliature in the ventral side reorganizes twice during sexual process, i.e., conjugational and postconjugational reorganization; (2) the adoral zone of membranelles (AZM) is generated de novo in a pouch beneath the cortex during both reorganizations, with the anterior part generated during the first reorganization, while the posterior part formed during the second reorganization; (3) the frontoventral-transverse (FVT) cirri anlagen are formed de novo in both processes with the fragmentation pattern of 2:2:3:3:2; (4) one left marginal cirrus is generated de novo during both reorganizations; and (5) the dorsal ciliature remains intact during the whole process, except that the two caudal cirri originate from the end of the right-most two dorsal kineties during both reorganizations. Comparisons of the morphogenetic process during conjugation demonstrate a considerably stable pattern within Euplotes while the patterns vary dramatically among different ciliate groups.

Keywords: ciliate, Euplotes raikovi, conjugation, morphogenesis, exconjugant

\section{INTRODUCTION}

Morphogenesis and pattern formation are important processes that occur in the organisms from unicellular to multicellular. It is driven by various cellular and developmental processes including cell proliferation, differentiation, apoptosis, cell migration, and cell adhesion (Jernvall and Newman, 2003). The morphogenesis process is mostly investigated in multicellular organisms, such as embryonic cells differentiating into various functional cell types, tissues, organs, and eventually forming a complex organism (Thomson et al., 1998; Reubinoff et al., 2000). Unicellular 
organisms have a high morphological diversity, which require more complex morphogenetic patterns. However, compared to the developmental biology in larger multicellular organisms, the morphogenesis in unicellular organisms is largely unknown (Shulman and Daniel, 1999; Kirschner et al., 2000).

Ciliated protozoans are a morphologically diverse and highly differentiated group among single-celled microorganisms (Song et al., 2009; Li et al., 2019; Wang et al., 2019; Yan et al., 2019; Sheng et al., 2020). The main characters of this group are dimorphic nuclei (both germline and somatic nuclei within one cell) and special sexual process of conjugation, during which there is a reciprocal exchange of haploid gametic nuclei between the two temporarily (most widespread) or totally (as in all peritrichs and chonotrichs) fused mating partners, although some ciliates can also perform autogamy, a process of self-fertilization undertaken by a single cell (Lynn, 2008). The morphogenesis in ciliates mainly includes the formation and regeneration of cortical structures and nuclei, which occurs in both asexual and sexual stages. Compared to that in asexual reproduction, the process is more complex during sexual stages (Diller, 1966; Jin et al., 1985; Zou and Ng, 1991; Ota and Taniguchi, 2003; Xu and Foissner, 2004; Gao et al., 2020).

As the most differentiated group within ciliates, species in the genus Euplotes Ehrenberg, 1830 are easy to collect, cultivate, and induce conjugation in the laboratory, which are ideal model organisms for investigating morphogenesis (Song and Shao, 2017; Chen et al., 2019; Jiang et al., 2019). Many investigations have been performed on the morphogenesis during binary fission of Euplotes species (Washburn and Borror, 1972; Ruffolo, 1976; Voss, 1989; Jiang et al., 2010; Shao et al., 2010; Song and Shao, 2017), while limited studies focus on the morphogenetic process during conjugation (Diller, 1966; Gao et al., 2020). Euplotes raikovi Agamaliev, 1966 is a widely distributed marine species that has been used in research on pheromone signaling and mating behaviors (Luporini et al., 2016). Morphology of E. raikovi has been redescribed in detail by Jiang et al. (2010): the adoral zone composed of 22-29 membranelles; invariably seven frontoventral, basal plaque V/2 composed of a single dikinetid, single marginal, two caudal, and five transverse cirri; seven to eight dorsal kineties (three to five dikinetids in leftmost kinety on ventral side), silverline system of double-patella-I type (Figure 1). The morphogenesis during binary fission and nuclear development during conjugation of E. raikovi have been well investigated (Washburn and Borror, 1972; Voss, 1989; Gong et al., 2020). In the present study, we investigate the morphogenesis of ciliature during conjugation and postconjugation of E. raikovi using living observation and protargol staining methods, which revealed two rounds of reorganization. The differences of the morphogenetic process between binary fission and conjugation within and among ciliate species are also compared and discussed.

\section{MATERIALS AND METHODS}

Two E. raikovi strains of different mating types (I and XIII) used extensively in previous research (Ricci et al., 2019) were selected in the present study. Cell culturing and conjugation induction were according to Gong et al. (2020). The mixed cells began to form mass mating pairs within $2 \mathrm{~h}$ and the ratio of conjugation was about $70 \%$. Mating pairs and the ex-conjugant cells were collected every hour and stained using protargol staining method (Gao et al., 2020). Drawings of stained specimens were performed with the help of a drawing device (Lu et al., 2020). Phylogenetic analyses were following Lian et al. (2019).

\section{RESULTS}

The whole process of conjugation lasts about $50 \mathrm{~h}$, including three prezygotic micronuclear divisions and two postzygotic synkaryon divisions (Figure 1H) (Gong et al., 2020). The ciliary structures in the ventral side reorganize twice during sexual stage. The first reorganization happens after the cells getting paired, here referred as conjugational reorganization, which lasts approximately $11-13 \mathrm{~h}$. About $25 \mathrm{~h}$ after the completion of the first reorganization, the second reorganization occurs during the late stage of macronuclear development, which is referred as postconjugational reorganization. The process is synchronized in each partner of a conjugating pair, so description based on one partner is as follows.

\section{Conjugational Reorganization Stomatogenesis}

About 3-5 h after cell-cell union, the old adoral zone of membranelles (AZM) and the paroral membrane of each partner in a conjugating pair were degraded gradually from posterior to anterior, and only a few apical membranelles were left (Figures 2A, 3A). Thereupon, the process of stomatogenesis was commenced in the form of a small patch of kinetosomes (Figures 2B, 3B), which appeared within a pouch beneath the cortex on the ventral side ahead of the marginal cirri. When this pouch started to enlarge, more and more kinetosomes aligned into new membranelles from the anterior to the posterior part to form the new oral primordium (OP). The newly reformed AZM gradually extended, bent, and migrated toward the anterior (Figures 2C-H, 3C-I). They finally reached half the length of the old AZM and replaced the remaining old AZM after the separation of conjugants (Figures 2I, 3J). The old apical membranes were completely resorbed and no paroral membrane was present during the conjugational morphogenesis.

\section{Development of Cirral Anlagen}

As the oral primordium extended, a number of basal bodies appeared as frontoventral-transverse (FVT) cirral anlagen, which were generated de novo to the anterior side of the old transverse cirri and right of the new oral primordium, and eventually developed into five distinct streaks (Figures 2E, 3E,F). These streaks extended to both directions by the proliferation of kinetosomes, and then broadened and broke apart in a 2:2:3:3:2 pattern, with each part developing into a new cirrus (Figures 2F,G, 3G,H), designated as the second generation cirri. Among them, the posterior one of each streak gradually moved posteriorly to be the five transverse cirri, and the 


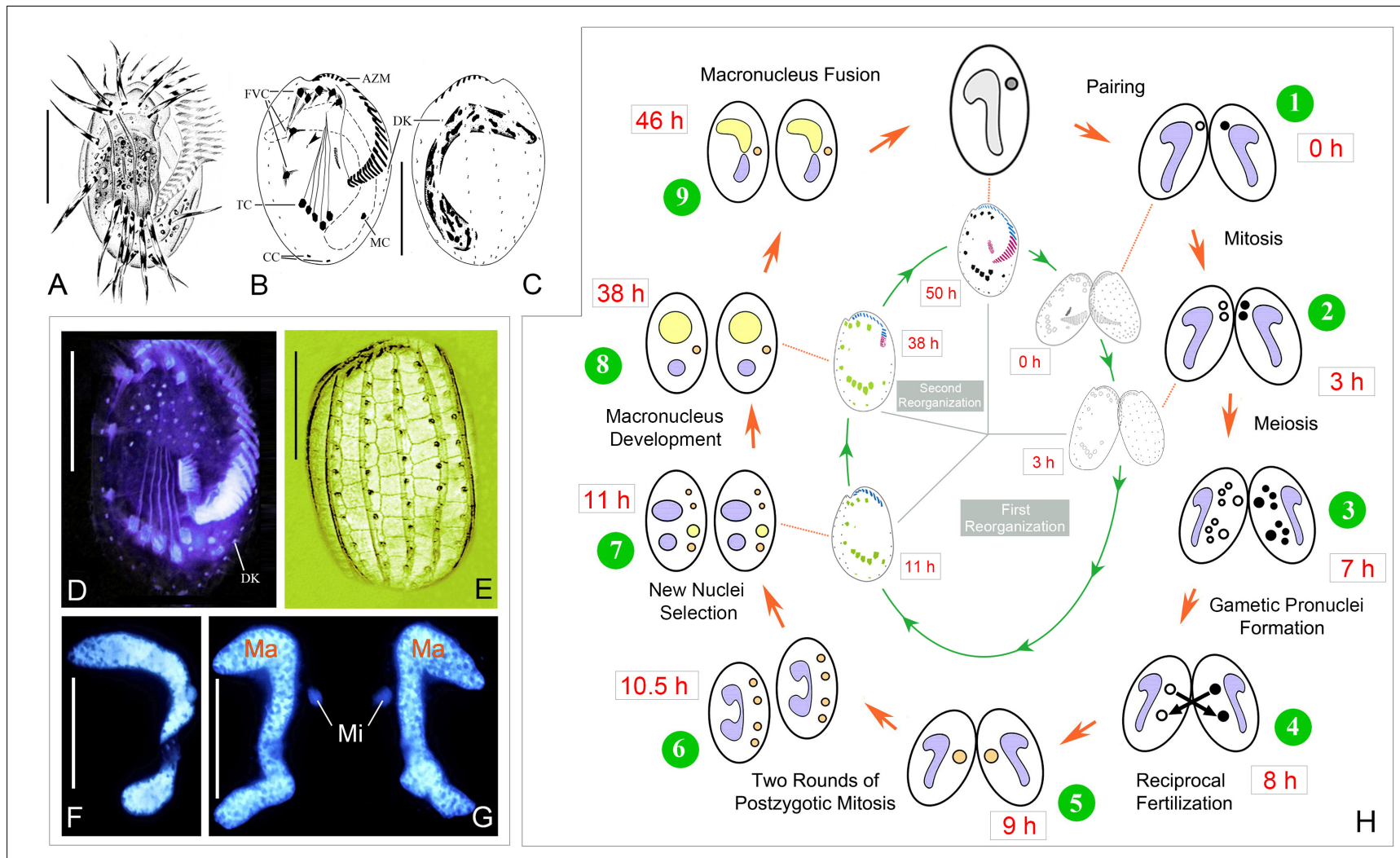

FIGURE 1 | Morphology and life cycle of Euplotes raikovi. (A-E) Euplotes raikovi in vivo (A), after protargol (B-D) and silver nitrate (E) staining, among which B, C, and $\mathrm{E}$ were from Jiang et al. (2010). (F,G) Hoechst 33342 staining to show the micronucleus and macronucleus in a vegetative cell (F) and a conjugating pair (G). (H) Nuclear events according to Gong et al. (2020) (outer) and morphogenesis during conjugation (inner). AZM, adoral zone of membranelles; CC, caudal cirri; DK, dorsal kineties; FVC, frontoventral cirri; Ma, macronucleus; MC, marginal cirrus; Mi, micronucleus; TC, transverse cirri; Scale bars = $30 \mu \mathrm{m}$.

others become fronto-ventral cirri with the middle one of the fourth streak gradually degenerating into a single dikinetid (Figures 2H,I, 3I,J).

A short row of kinetosomes appeared de novo near the old marginal cirrus, and assembled into the marginal cirral anlage (Figures 2G, 3H). This anlage finally developed into the second generation marginal cirrus, which migrated and replaced the old one (Figures 2H,I, 3I,J).

One cirrus anlage originated at the posterior end of each of the rightmost two dorsal kineties, which later proliferated and developed into two new caudal cirri (Figures 2G, 3H).

\section{Postconjugational Reorganization}

\section{Stomatogenesis}

After the first round of reorganization, the posterior part of the AZM, the paroral membrane, and the leftmost frontal cirrus were still missing (Figures 2I, 3J). The exconjugants then initiated the second round of morphogenesis at about $36-38 \mathrm{~h}$ after cells union. Some kinetosomes started aggregating at the posterior termination of the incomplete AZM (Figure 2J), which then assembled into new adoral membranelles from anterior to posterior directions and finally form the complete AZM (Figures 2K-M, 3L-N). The paroral membrane primordium appeared within a subcortical pouch near the posterior end of the oral primordium (Figures $\mathbf{2 L}, \mathbf{M}, \mathbf{3} \mathbf{M}, \mathbf{N}$ ). This paroral membrane primordium elongated and broadened and eventually developed into the paroral membrane.

\section{Development of Cirral Anlagen}

Similar to the conjugational reorganization, the anlagen of the FVT cirri appeared de novo almost at the same location as in the first round of reorganization (Figures $2 \mathbf{K}, 3 \mathbf{K}$ ). These anlagen broadened and broke apart into five streaks in a 2:2:3:3:2 pattern, which then developed into distinct cirri (Figures 2L,M, 3L,M). At the same time, another anlage (Figure 2K) appeared to the left of streaks near the new AZM, then developed into the left-most frontal cirrus (Figures 2L,M, 3L,M). All the cirri migrated to their final positions after differentiation and eventually replaced the old ones (Figures $2 \mathrm{~N}, 3 \mathbf{N}$ ).

Similarly, one anlage of the marginal cirrus appeared de novo, near the distal end of the newly formed oral primordium (Figures 2L, 3L). Kinetosomes continuously aggregated and developed into the new marginal cirrus (Figures 2M, 3M), which moved to its final position and replaced the second generation marginal cirrus.

Same as in the conjugational reorganization, short rows of basal bodies assembled into anlagen at the posterior end of each of the rightmost two dorsal kineties (Figures 2L,M, 3M). 

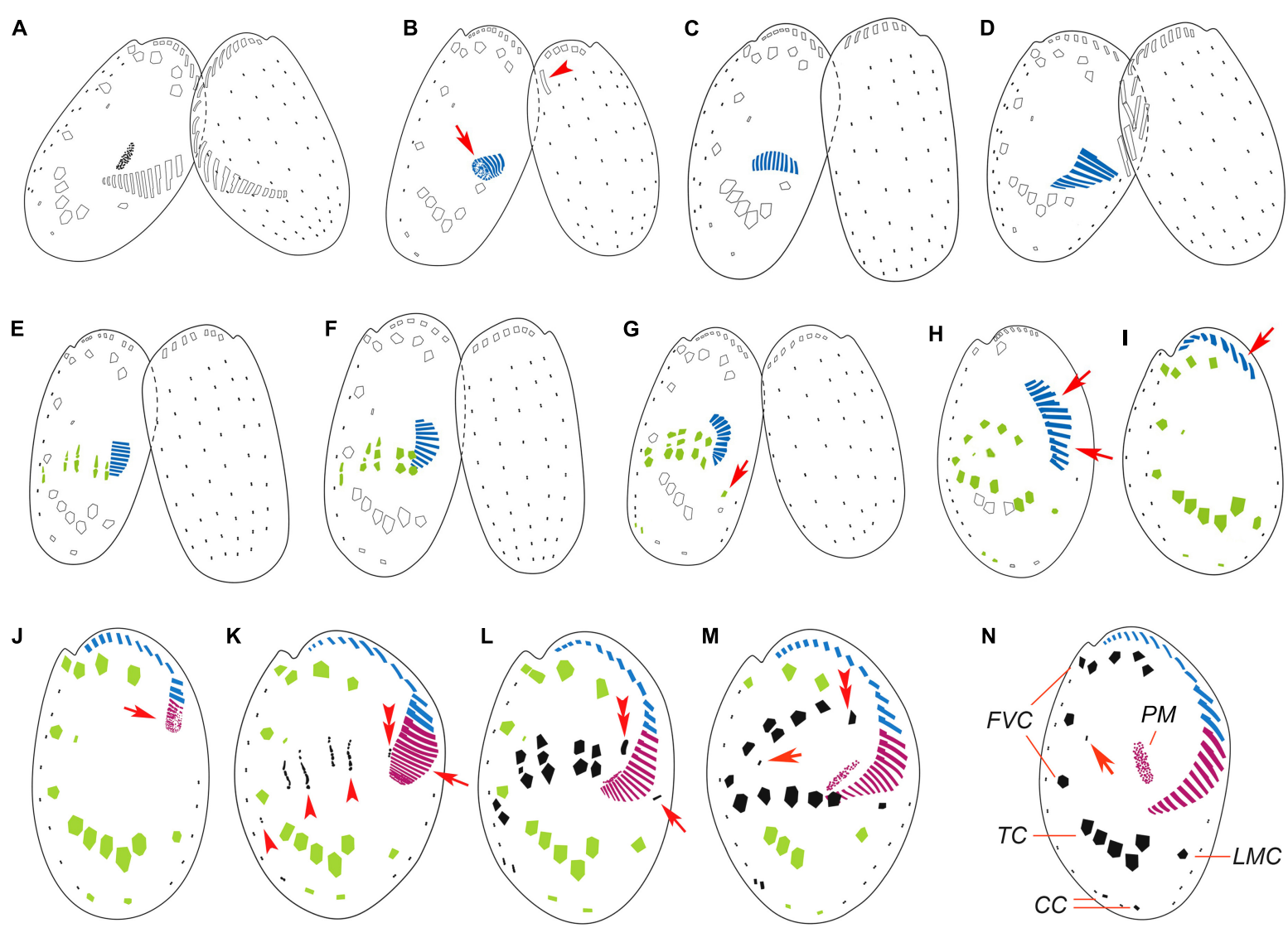

FIGURE 2 | |llustrations of the morphogenesis in conjugants (A-G) and exconjugants (H-M) after protargol staining. (A) Initiation of conjugation showing fusion of old adoral zone of membranelles (AZM) among the two partners. (B-D) Start of conjugational morphogenesis showing the formation of new oral primordium (arrow) and the disintegration of the parental one (arrowhead). (E-G) Late stages of conjugants showing formation of new adoral membranelles, frontoventral-transverse (FVT) cirri anlagen, marginal cirral anlagen (arrow in G), and caudal cirral anlagen. (H,I) Early exconjugants showing the migration of the incomplete AZM (arrows) and ventral cirri to their respective positions. (J) Start of postconjugational morphogenesis showing the formation of the new oral primordium (arrow). (K) Late stage exconjugant showing the formation of new membranelles in AZM (arrow), FVT cirri anlagen (arrowheads), and leftmost frontal cirrus anlage (double arrowheads). (L-N) Series of late exconjugants showing completion of AZM, development of FVT cirri, marginal cirrus (arrow in L), the leftmost frontal cirrus (double arrowheads in $\mathbf{L}$ and $\mathbf{M}$ ), and the reduced cirrus (arrows in $\mathbf{M}$ and $\mathbf{N}$ ). CC, caudal cirri; FVC, frontoventral cirri; LMC, left marginal cirrus; TC, transverse cirri; PM, paroral membrane.

Eventually, two new caudal cirri were formed, which migrated and replaced the second generation caudal cirri.

\section{DISCUSSION}

\section{Comparison of the Conjugational and Postconjugational Reorganization in E. raikovi}

The ciliature in the ventral side goes through two rounds of morphogenetic process during sexual stage in E. raikovi. The morphogenetic events during conjugational and postconjugational reorganization are similar in that: (1) the FVT cirral anlagen originate de novo in a 2:2:3:3:2 pattern; (2) the marginal cirral anlage is generated de novo; (3) the dorsal kineties remain unchanged during both reorganization, except that the two caudal cirri are regenerated at the posterior ends of the rightmost two dorsal kineties.
There are also some significant differences between the two processes. First, although the oral primordium is generated de novo in a pouch beneath the cortex during both reorganizations, only the anterior part of the AZM is generated during the conjugational reorganization while the posterior part is formed during the postconjugational reorganization. Second, the parental paroral membrane degrades immediately after the pair formation, but no new one forms during conjugational reorganization. The new paroral membrane develops de novo during postconjugational reorganization. Third, the leftmost frontal cirrus is absent during the conjugational morphogenesis while it is formed de novo during the postconjugational reorganization only.

It seems that the first round of reorganization is a waste of energy, which is redundant. Maybe the first round of reorganization is simply triggered by the degradation of the peristome, which have to be destroyed temporally for the pairs to fusion. The other explanation is that the morphogenesis may be coupled with the nuclear division, which is similar to that 


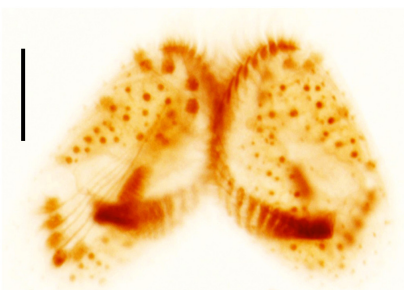

A
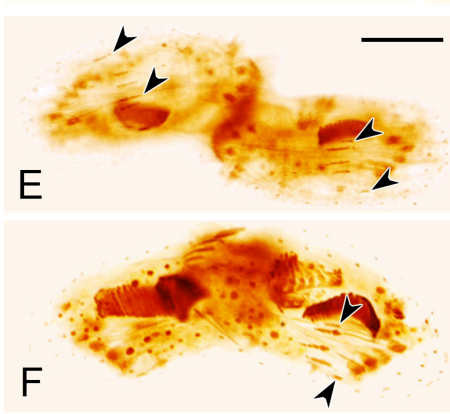

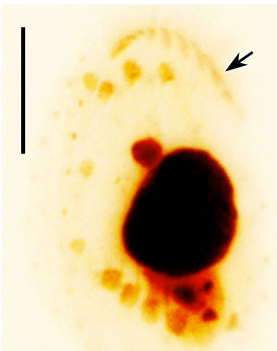

$J$

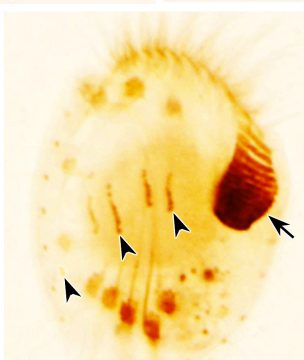

K

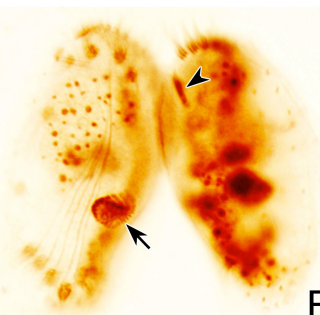

B

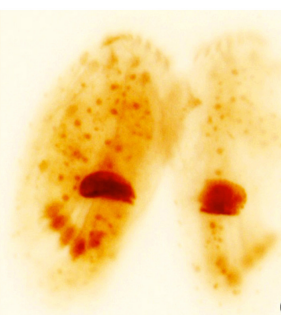

C
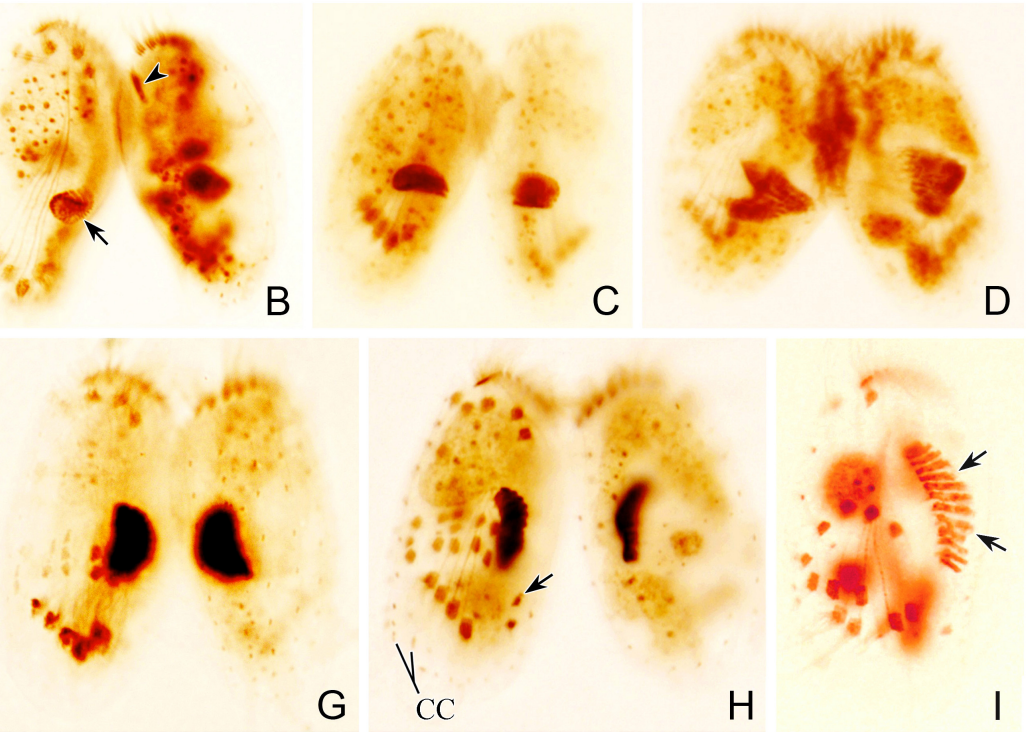

D

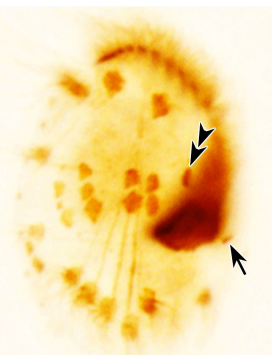

$\mathrm{L}$
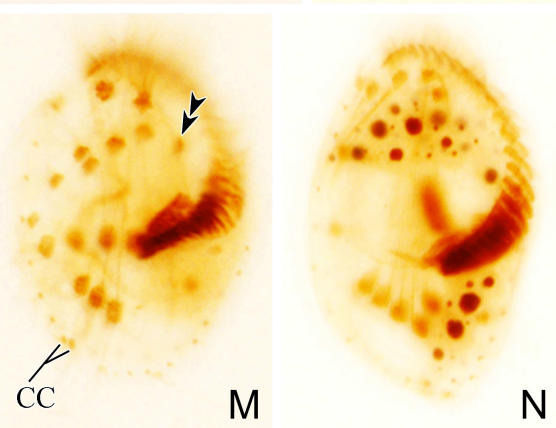

FIGURE 3 | Photomicrographs of morphogenesis of conjugants (A-H) and exconjugants (I-N) after protargol staining. (A) Very early conjugant showing formation of conjugational junction. (B) Early stage conjugant showing the origination of oral primordium in a subcortical pouch (arrow) and the disintegration of the parental one (arrowhead). (C,D) Conjugants showing formation of new adoral membranelles in the newly developed adoral zone of membranelles (AZM). (E,F) Conjugants showing frontoventral-transverse (FVT) cirri anlagen (arrowheads). (G,H) Late stage conjugants showing FVT cirri anlagen, broaden and break apart into definite cirri, one marginal cirrus (arrow in $\mathbf{H}$ ) originates near distal end of newly formed AZM. (I,J) Early exconjugants showing migration of the anterior part of AZM (arrows) and FVT cirri. (K) Exconjugant showing the initiation of postconjugational morphogenesis, formation of new AZM (arrow), and FVT cirri anlagen (arrowheads). (L) Exconjugant showing proliferation and differentiation of FVT cirri, the leftmost frontal cirrus (double arrowheads), and the marginal cirrus anlage (arrow). (M,N) Series of late exconjugants showing the completed AZM, development of FVT cirri, two caudal cirri (CC in $\mathbf{M}$ ), and the leftmost frontal cirrus (double arrowheads in $\mathbf{M}$ ). Scale bars $=20 \mu \mathrm{m}$.

during cell division (Washburn and Borror, 1972; Voss, 1989). There is one prezygotic micronuclear mitosis and two successive postzygotic synkaryon divisions during conjugation (Gong et al., 2020), which may be related to the two rounds of reorganization.

\section{Comparison of Morphogenesis During Asexual and Sexual Stages in E. raikovi}

Regeneration of cortical structures occurs in both asexual (Washburn and Borror, 1972; Voss, 1989), and sexual stages in E. raikovi. The morphogenetic patterns during conjugation and cell division are similar in the origin and segmentation of the FVT cirral anlagen, the absence/presence of reduced cirrus, and the developmental pattern of the caudal and marginal cirri. The differences of morphogenetic observations between conjugation and cell division are as follows: (1) two rounds of reorganization occur during the conjugation of E. raikovi, while only one morphogenesis happens during cell division; (2) the new AZM develops de novo from two separate and successive oral primordia during conjugation, while the proter's AZM is inherited from the parental AZM and the opisthe's is generated de novo from a single oral primordium during cell division; (3) there is one set of the FVT cirral anlagen in each reorganization during conjugation while there are two sets during cell division, which are assigned respectively to the opisthe and proter; and (4) the dorsal kineties remain unchanged during conjugation, while they are renewed during cell division.

\section{Comparison of Morphogenesis Among Euplotes Species}

Euplotes is a very diverse genus of ciliate group, over 100 species and sub-species have been discovered and assigned to the genus Euplotes (Berger, 2001; Lian et al., 2020). The 
morphogenesis during cell division have been investigated in detail in $\sim 20$ Euplotes species, which demonstrate a considerably stable pattern of cell development (Tuffrau et al., 1976; Voss, 1989; Foissner, 1996; Song and Shao, 2017). Comparatively, morphogenesis during conjugation have been studied in only eight species, E. vannus (Tuffrau et al., 1976; Gao et al., 2020), E. affinis (Qeng et al., 1992), E. eurystomus (Katashima, 1959), E. aediculatus (Fleury, 1991), E. woodruffi (Wang and Shi, 1989), E. patella (Turner, 1930; Hammond and Kofoid, 1937), an indeterminate Euplotes species (Diller, 1966), and E. raikovi in the present study, which reveal similar patterns. They all go through two rounds of morphogenetic process during conjugation. The first reorganization generates an incomplete ventral infraciliature, lacking the posterior part of AZM, the leftmost frontal cirrus and paroral membrane, which will be completed by the second reorganization. One exception is E. eurystomus, which was reported to have only one reorganization during conjugation (Katashima, 1959). Considering the highly conservative pattern among Euplotes species, it is very likely that the author missed the first reorganization. It is noteworthy that reorganization of the dorsal kineties is not observed during conjugation in E. raikovi, which is consistent with that in other Euplotes species except for E. affinis. Qeng et al. (1992) investigated the conjugation in E. affinis based on protargol staining. They observed the regeneration of dorsal kineties during the postconjugational reorganization (Qeng et al., 1992).

The morphogenetic patterns during conjugation among Euplotes species vary slightly mainly in the development of the FVT and caudal cirri, which is similar to those during binary fission (Shao et al., 2010). Based on the origin and number of the FVT, the segmentation of the FVT cirral anlagen, the absence/presence of reduced cirrus, and the migration of the FVT cirri, at least five types are defined, including the affinistype, the eurystomus-type, the charon-type, the raikovi-type, and the orientalis-type (Shao et al., 2010). E. raikovi is obviously the raikovi-type of 2:2:3:2 (+1):2 (7 frontoventral, 1 reduced cirrus, and 5 transverse cirri). E. vannus belongs to the charon-type of 3:3:3:2:2 (10 frontoventral and 5 transverse cirri) (Tuffrau et al., 1976; Gong et al., 2020). E. eurystomus, E. aediculatus, E. woodruffi, and E. patella belong to the eurystomus-type of 3:3:3:2:2 (nine frontoventral and five transverse cirri, cirrus V/2 clearly medial of cirrus VI/2) (Turner, 1930; Hammond and Kofoid, 1937; Katashima, 1959; Wang and Shi, 1989; Fleury, 1991). E. affinis is the affinis-type of 3:3:3:2:2 (nine frontoventral and five transverse cirri, cirrus $\mathrm{V} / 2$ directly anterior to cirrus VI/2) (Qeng et al., 1992).

We mapped the characters (the number of the FVT cirri and the segmentation of the FVT cirral anlagen) of the available Euplotes species into the phylogenetic trees based on SSU rDNA, which divides the Euplotes species into five clades (Figure 4). Based on the present data, species in clades 1, 4 , and 5 possess 10 frontoventral cirri and 5 transverse cirri with the segmentation pattern of $3: 3: 3: 3: 2$, which might be plesiomorphy in Euplotes, though two frontoventral cirri are reduced in E. orientalis. Comparatively, species in clade 2 lose one frontoventral cirrus, with nine frontoventral cirri and five transverse cirri and the segmentation pattern of $3: 3: 3: 2: 2$. Species in clade 3 lose two frontoventral cirri, with eight frontoventral cirri and five transverse cirri and 2:2:3:3:2 pattern. In general, Euplotes species tend to lose their frontoventral cirri, which may occur independently among different subgroups (Zhao et al., 2018).

\section{Morphogenesis During Sexual Stages in Other Ciliates}

Limited studies reveal that the patterns of morphogenesis during conjugation vary dramatically among ciliates. For example, there is no obvious reorganization during conjugation in Protospathidium serpens, which unite obliquely with the oral bulge (Xu and Foissner, 2004). Only oral structures are reorganized during the conjugation in some species such as Paramecium tetraurelia (Ng and Newman, 1984), Urocentrum turbo (Serrano et al., 1987), Caenomorpha medusula (MartinGonzalez et al., 1988), Nyctotherus cordiformis (Wichterman, 1937), and Bursaria truncatella (Poljansky, 1934), although this reorganization of oral structures may occur at different developmental stages during conjugation, which is taxa specific. It has been indicated that ciliates go through a similar nuclear and cortical reorganization during autogamy as in conjugation (Xu and Shi, 1987). As research focusing on morphogenesis during autogamy is very limited, we only discuss the morphogenetic process during conjugation.

The most complex reorganization of the ciliature, including reorganization of both the buccal organelles and somatic ciliature, occurs in conjugating spirotrichs, which has conspicuous oral ciliature and highly differentiated somatic ciliature (Xu et al., 2020; Zhang et al., 2020). The ciliary reorganization during conjugation may occur only once as reported in Pelagostrobilidium sp. (Ota and Taniguchi, 2003) and Halteria grandinella (Agatha and Foissner, 2009), twice as in Euplotes (present study) and Aspidisca (Diller, 1975), and even three times as in Oxytricha fallax (Gregory, 1923), Stylonychia mytilus (Shi, 1976), and Pseudourostyla cristata (Zhang et al., 1985). Despite being a close relative to E. raikovi and two rounds of reorganizations occur during conjugation in both species, Aspidisca costata showed a different developmental behavior. In Aspidisca, the old AZM disintegrate but the new AZM is not developed until in late exconjugants during the second reorganization, so that the exconjugants remained astomatous for a long time (Diller, 1975; Rosati et al., 1998). However, Aspidisca species develop an anterior ciliary organelles (ACO) during the first reorganization, which corresponds to the anterior part of Euplotes AZM. Moreover, in both genera, the left most frontal cirrus develops only once. In Aspidisca, it originates during the first reorganization while in Euplotes during the second reorganization (Rosati et al., 1998). Therefore, a full number of cirri is developed after the first reorganization in Aspidisca while it is still incomplete in Euplotes. As mentioned above, it is obvious that many cytoplasmic organelles generally undergo profound reorganization during conjugation, which display a very high diversity of the morphogenetic patterns among ciliates. The 


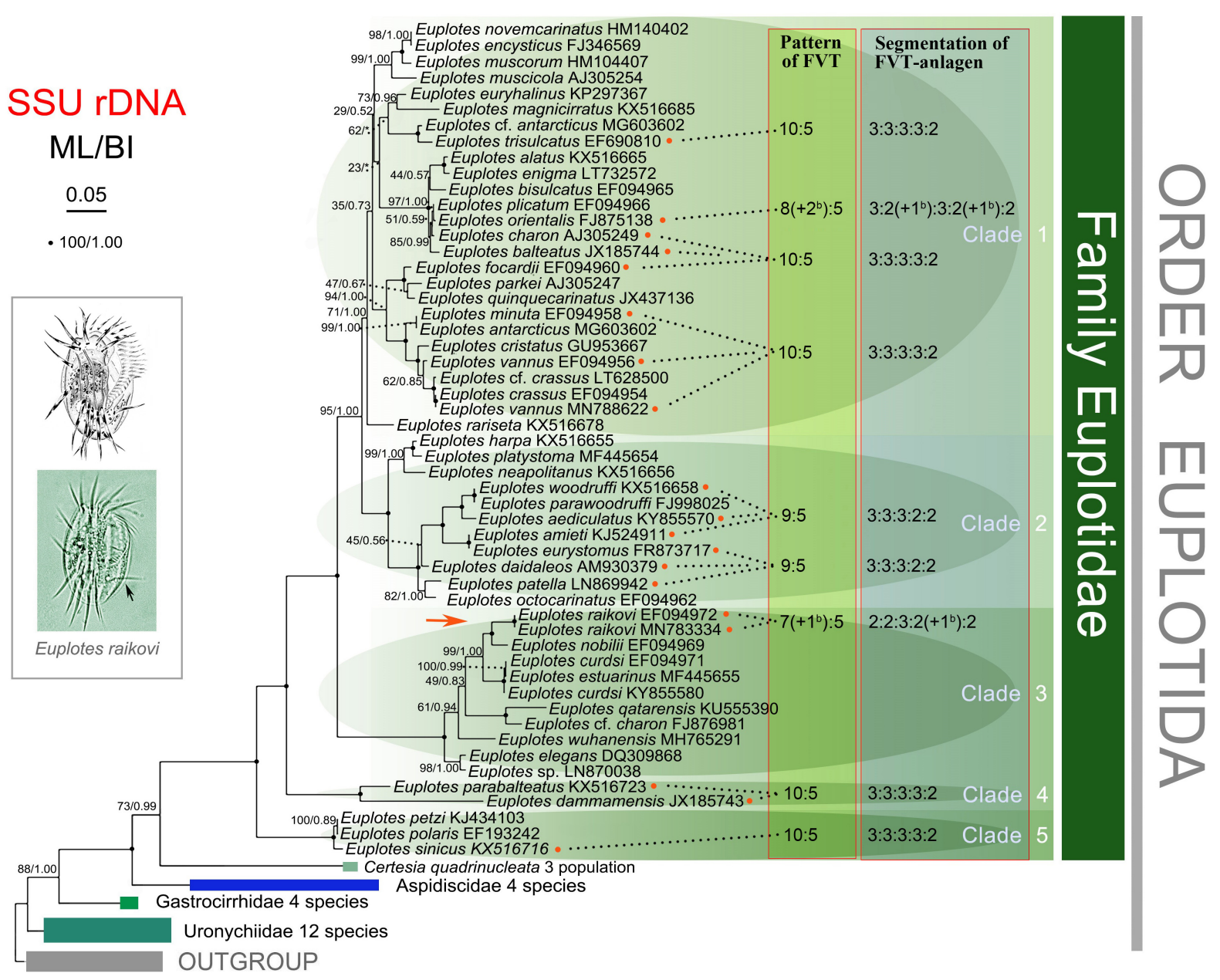

FIGURE 4 | Maximum likelihood (ML) tree based on SSU rDNA sequences showing the evolutionary relationships among Euplotes species. The pattern and the segmentation of the frontoventral-transverse (FVT) cirri of the available species are indicated in the tree. The FVT pattern represents the number of frontoventral cirri: transverse cirri. The segmentation of the FVT cirri shows the number of the fragmented anlagen from the first streak to the fifth streak, and the number of additional barren cirri/anlagen is shown in brackets. Numbers near the branches represent bootstrap values of $\mathrm{ML}$ analyses and posterior probability of Bayesian analyses (Bl). "** indicates topologies that differ between the ML and BI phylogenies. Fully supported (100/1.00) branches are marked with solid circles. All branches are drawn to scale. The scale bar corresponds to 5 substitutions per 100 nucleotide positions.

deep molecular mechanisms related to this complex process are waiting for further investigations.

\section{DATA AVAILABILITY STATEMENT}

The original contributions presented in the study are included in the article/supplementary material, further inquiries can be directed to the corresponding author/s.

\section{AUTHOR CONTRIBUTIONS}

FG performed conceptualization, supervision, and funding acquisition. RG performing cell culturing and conjugation induction. UA and YC performing protargol staining. BL performing drawings. YG performing phylogenetic analyses.
YJ performing Figure 1 preparation. UA, YC, YG, BL, YJ, RG, HM, KA, and FG performing original draft, review, and editing. All authors contributed to the article and approved the submitted version.

\section{FUNDING}

This work was supported by the National Natural Science Foundation of China (Project Nos. 31922013, 31772428, and 32030015) and Research Supporting Project (RSP-2020/10), King Saud University, Saudi Arabia.

\section{ACKNOWLEDGMENTS}

We thank Prof. Weibo Song (OUC) and the two reviewers for their kind help in revising the manuscript. 


\section{REFERENCES}

Agatha, S., and Foissner, W. (2009). Conjugation in the spirotrich ciliate Halteria grandinella (Müller, 1773) Dujardin, 1841 (Protozoa, Ciliophora) and its phylogenetic implications. Eur. J. Protistol. 45, 51-63. doi: 10.1016/j.ejop.2008. 07.004

Berger, H. (2001). Catalogue of ciliate names: 1. Hypotrichs. Salzburg: Verlag Helmut Berger.

Chen, X., Jiang, Y. H., Gao, F., Zheng, W. B., Krock, T. J., Stover, N. A., et al. (2019). Genome analyses of the new model protist Euplotes vannus focusing on genome rearrangement and resistance to environmental stressors. Mol. Ecol. Resour. 19, 1292-1308. doi: 10.1111/1755-0998.13023

Diller, W. F. (1966). Correlation of ciliary and nuclear development in the life cycle of Euplotes. J. Protozool. 13, 43-54. doi: 10.1111/j.1550-7408.1966.tb01868.x

Diller, W. F. (1975). Nuclear behavior and morphogenetic changes in fission and conjugation of Aspidisca costata (Dujardin). J. Protozool. 22, 221-229. doi: 10.1111/j.1550-7408.1975.tb05855.x

Fleury, A. (1991). Dynamics of the cytoskeleton during morphogenesis in the ciliate Euplotes. Eur. J. Protistol. 27, 220-237. doi: 10.1016/S0932-4739(11)80060-X

Foissner, W. (1996). Ontogenesis in ciliated protozoa with emphasis on stomatogenesis. Hausmann Stuttgart: Gustav Fisher Verlag.

Gao, Y., Gong, R., Jiang, Y., Pan, B., Li, Y., Warren, A., et al. (2020). Morphogenetic characters of the model ciliate Euplotes vannus (Ciliophora, Spirotrichea): Notes on cortical pattern formation during conjugational and postconjugational reorganization. Eur. J. Protistol. 73:125675. doi: 10.1016/j.ejop.2020.125675

Gong, R., Jiang, Y., Vallesi, A., Gao, Y., and Gao, F. (2020). Conjugation in Euplotes raikovi (Protista, ciliophora): New insights into nuclear events and macronuclear development from micronucleate and amicronucleate cells. Microorganisms 8:162. doi: 10.3390/microorganisms 8020162

Gregory, L. H. (1923). The conjugation of Oxytricha fallax. J. Morphol. 37, 555-581. doi: 10.1002/jmor.1050370305

Hammond, D. M., and Kofoid, C. A. (1937). The continuity of structure and function in the neuromotor system of Euplotes patella during its life cycle. Proc. Am. Philos. Soc. 77, 207-218.

Jernvall, J., and Newman, S. (2003). Mechanisms of pattern formation in development and evolution. Development 130, 2027-2037. doi: 10.1242/dev. 00425

Jiang, J., Zhang, Q., Warren, A., Al-Rasheid, K. A. S., and Song, W. (2010). Morphology and SSU rRNA gene-based phylogeny of two marine Euplotes species, E. orientalis spec. nov. and E. raikovi Agamaliev, 1966 (Ciliophora, Euplotida). Eur. J. Protistol. 46, 121-132. doi: 10.1016/j.ejop.2009.11.003

Jiang, Y., Zhang, T., Vallesi, A., Yang, X., and Gao, F. (2019). Time-course analysis of nuclear events during conjugation in the marine ciliate Euplotes vannus and comparison with other ciliates (Protozoa, Ciliophora). Cell Cycle 18, 288-298. doi: 10.1080/15384101.2018.1558871

Jin, L. P., Zhuang, H., and Tsorun, T. (1985). Studies on conjugation in Pseudourostyla cristata â .Nucleogenesis. Zool. Res. 6, 159-167.

Katashima, R. (1959). A correlation between morphogenesis and old macronucleus during sexual reproduction in Euplotes eurystomus. J. Sci. Hiroshima Univ. Ser. B 19, 99-107.

Kirschner, M., Gerhart, J., and Mitchison, T. (2000). Molecular “vitalism.”. Cell 100, 79-88. doi: 10.1016/s0092-8674(00)81685-2

Li, X., Huang, J., Filker, S., Stoeck, T., Bi, Y., Yu, Y., et al. (2019). Spatio-temporal patterns of zooplankton in a main-stem dam affected tributary: a case study in the Xiangxi River of the Three Gorges Reservoir, China. Sci. China Life Sci. 62, 1058-1069. doi: 10.1007/s11427-018-9523-0

Lian, C., Wang, Y., Li, L., Al-Rasheid, K., Jiang, J., and Song, W. (2020). Taxonomy and SSU rDNA-based phylogeny of three new Euplotes species (Protozoa, Ciliophora) from China seas. J. King Saud Univ. 32, 1286-1292. doi: 10.1016/ j.jksus.2019.11.013

Lian, C., Zhang, T., Al-Rasheid, K. A. S., Yu, Y., Jiang, J., and Huang, J. (2019). Morphology and SSU rDNA-based phylogeny of two Euplotes species from China: E. wuhanensis sp. n. and E. muscicola Kahl, 1932 (Ciliophora, Euplotida). Eur. J. Protistol. 67, 1-14. doi: 10.1016/j.ejop.2018.10.001

Lu, B., Shen, Z., Zhang, Q., Hu, X., Warren, A., and Song, W. (2020). Morphology and molecular analyses of four epibiotic peritrichs on crustacean and polychaete hosts, including descriptions of two new species (Ciliophora, Peritrichia). Eur. J. Protistol. 73:125670. doi: 10.1016/j.ejop.2019.125670
Luporini, P., Pedrini, B., Alimenti, C., and Vallesi, A. (2016). Revisiting fifty years of research on pheromone signaling in ciliates. Eur. J. Protistol. 55, 26-38. doi: 10.1016/j.ejop.2016.04.006

Lynn, D. H. (2008). The ciliated protozoa: Characterization, classification, and guide to the literature, 3rd Edn. Dordrecht: Springer Press, doi: 10.1007/978-1-40208239-9

Martin-Gonzalez, A., Serrano, S., and Fernández-Galiano, D. (1988). Cortical morphogenesis and conjugation process in Caenomorpha medusula (Ciliophora, Heterotrichida). Eur. J. Protistol. 23, 111-121. doi: 10.1016/S0932-4739(88)80054-3

Ng, S. F., and Newman, A. (1984). The role of the micronucleus in stomatogenesis in sexual reproduction of Paramecium tetraurelia: micronuclear and stomatogenic events. Protistol. 20, 43-64. doi: 10.1016/s0932-4739(87) 80006-8

Ota, T., and Taniguchi, A. (2003). Conjugation in the marine aloricate oligotrich Pelagostrobilidium (Ciliophora: Oligotrichia). Eur. J. Protistol. 39, 149-160. doi: 10.1078/0932-4739-00878

Poljansky, G. (1934). Geschlechtsprozesse bei Bursaria truncatella O.F. Mull. Arch. Protistenk. 81, 420-456.

Qeng, Y., Zou, S., and Tchang, T. (1992). The morphological changes in conjugation of Euplote affiniss. J. East China Norm. Univ. Nat. Sci. 2, 81-89.

Reubinoff, B. E., Pera, M. F., Fong, C. Y., Trounson, A., and Bongso, A. (2000). Embryonic stem cell lines from human blastocysts: Somatic differentiation in vitro. Nat. Biotechnol. 18, 399-404. doi: 10.1038/74447

Ricci, F., Candelori, A., Brandi, A., Alimenti, C., Luporini, P., and Vallesi, A. (2019). The sub-chromosomic macronuclear pheromone genes of the ciliate Euplotes raikovi: comparative structural analysis and insights into the mechanism of expression. J. Eukaryot. Microbiol. 66, 376-384. doi: 10.1111/jeu.12677

Rosati, G., Verni, F., and Dini, F. (1998). Mating by conjugation in two species of the genus Aspidisca (Ciliata, Hypotrichida): an electron microscopic study. Zoomorphology 118, 1-12. doi: 10.1007/s004350050051

Ruffolo, J. J. (1976). Cortical morphogenesis during the cell division cycle in Euplotes: An integrated study using light optical, scanning electron and transnlission electron microscopy. J. Morphol. 148, 489-527. doi: 10.1002/jmor. 1051480406

Serrano, S., Martin-Gonzalez, A., and Fernandez-Galiano, D. (1987). Nuclear phenomena and oral reorganization during the conjugation of Urocentrum turbo OFM (Ciliata). Arch. für Protistenkd. 133, 257-268. doi: 10.1016/S00039365(87)80058-1

Shao, C., Ma, H., Gao, S., Khaled, A. R. A., and Song, W. (2010). Reevaluation of cortical developmental patterns in Euplotes (s. 1.), including a morphogenetic redescription of E. charon (Protozoa. Ciliophora, Euplotida). Chinese J. Oceanol. Limnol. 28, 593-602. doi: 10.1007/s00343-010-9128-9

Sheng, Y., Duan, L., Cheng, T., Qiao, Y., Stover, N. A., and Gao, S. (2020). The completed macronuclear genome of a model ciliate Tetrahymena thermophila and its application in genome scrambling and copy number analyses. Sci. China Life Sci. 63, 1534-1542. doi: 10.1007/s11427-020-1689-4

Shi, X. (1976). Studies on conjugation in Stylonychyia mytilus II. Morphogenesis of argentophilic system. Acta Zool. Sin. 22, 71-83.

Shulman, J. M., and Daniel, S. J. (1999). Pattern formation in single cells. Trends Biochem. Sci. 24, 60-64. doi: 10.1016/S0968-0004(99)01490-5

Song, W., and Shao, C. (2017). Ontogenetic patterns of hypotrich ciliates. Beijing: Science Press.

Song, W., Warren, A., and Hu, X. (2009). Free-living ciliates in the Bohai and Yellow Seas, China. Beijing: Science Press.

Thomson, J. A., Itskovitz-Eldor, J., Shapiro, S. S., Waknitz, M. A., Swiergiel, J. J., Marshall, V. S., et al. (1998). Embryonic stem cell lines derived from human blastocysts. Science 282, 1145-1147. doi: 10.1126/science.282.5391. 1145

Tuffrau, M., Tuffrau, H., and Genermont, J. (1976). La réorganisation infraciliaire au cours de la conjugaison et l'origine du primordium buccal dans le genre Euplotes. J. Protozool. 23, 517-523. doi: 10.1111/j.1550-7408.1976.tb03830.x

Turner, J. P. (1930). Division and conjugation in Euplotes patella Ehrenberg with special reference to the nuclear phenomena. Univ. Calif. Publ. Zool. 33, $193-258$.

Voss, H. (1989). Morphogenetic comparison of 13 species of the genus Euplotes (ciliophora, hypotrichida). Arch. für Protist. 137, 331-344. doi: 10.1016/s00039365(89)80016-8 
Wang, H., and Shi, X. (1989). Studies on morphogenesis accompanying binary fission and conjugation in Euplotes woodruffi (Ciliata, Protozoa). Acta Zool. Sin. 35, 353-359.

Wang, Y., Sheng, Y., Liu, Y., Zhang, W., Cheng, T., Duan, L., et al. (2019). A distinct class of eukaryotic MT-A70 methyltransferases maintain symmetric DNA $\mathrm{N}^{6}$-adenine methylation at the ApT dinucleotides as an epigenetic mark associated with transcription. Nucleic. Acids Res. 47, 11771-11789. doi: 10.1093/ nar/gkz1053

Washburn, E. S., and Borror, A. C. (1972). Euplotes raikovi Agamaliev, 1966 (Ciliophora, Hypotrichida) from new hampshire: description and morphogenesis. J. Protozool. 19, 604-608. doi: 10.1111/j.1550-7408.1972.tb03541.x

Wichterman, R. (1937). Division and conjugation in Nyctotherus cordiformis (EHr.) Stein (Protozoa, Ciliata) with special reference to the nuclear phenomena. J. Morphol. 60, 563-611. doi: 10.1002/jmor.1050600212

$\mathrm{Xu}, \mathrm{K}$, and Foissner, W. (2004). Body, nuclear, and ciliary changes during conjugation of Protospathidium serpens (Ciliophora, Haptoria). J. Eukaryot. Microbiol. 51, 605-617. doi: 10.1111/j.1550-7408.2004.tb00594.x

Xu, W., Wang, Y., Cheng, T., Yu, Y., El-Serehy, H., Al-Farraj, S. A., et al. (2020). Reevaluation of the 'well-known' Paraurostyla weissei complex, with notes on the ontogenesis of a new Paraurostyla species (Ciliophora, Hypotrichia). Eur. J. Protistol. 73:125672. doi: 10.1016/j.ejop.2020.125672

$\mathrm{Xu}, \mathrm{Z}$., and Shi, X. (1987). Research on initiation of sexual reproduction and induced autogamy in Stylonychia mythus. Acta Zool. Sin. 33, 353-361.

Yan, Y., Maurer-Alcalá, X. X., Kosakovsky Pond, S. L., Knight, R., and Katz, L. A. (2019). Single-cell transcriptomics reveal a correlation between genome architecture and gene family evolution in ciliates. mBio. 10:e02524-19. doi: 10.1128/mBio.02524- 19
Zhang, T., Dong, J., Cheng, T., Duan, L., and Shao, C. (2020). Reconsideration of the taxonomy of the marine ciliate Neobakuella aenigmatica Moon et al., 2019 (Protozoa, Ciliophora, Hypotrichia). Mar. Life Sci. Technol. 2, 97-108. doi: 10.1007/s42995-020-00032-4

Zhang, Z., Zhuang, H., and Jin, L. P. (1985). Studies on Conjugation in Pseudourostyla cristata II. Morphogenesis of Cortical Structures. Zool. Res. 6, 79-92.

Zhao, Y., Yi, Z., Warren, A., and Song, W. (2018). Species delimitation for the molecular taxonomy and ecology of the widely distributed microbial eukaryote genus Euplotes (Alveolata, Ciliophora). Proc. R. Soc. B Biol. Sci. 285:20172159. doi: $10.1098 / \mathrm{rspb} .2017 .2159$

Zou, S. F., and Ng, S. F. (1991). Commitment to the first cortical reorganization during conjugation in Stylonychia mytilus: An argument for homology with cortical development during binary fission. J. Protozool. 38, 192-200. doi: 10. 1111/j.1550-7408.1991.tb04428.x

Conflict of Interest: The authors declare that the research was conducted in the absence of any commercial or financial relationships that could be construed as a potential conflict of interest.

Copyright (c) 2021 Asghar, Chi, Gao, Lu, Jiang, Gong, Ma, Al-Rasheid and Gao. This is an open-access article distributed under the terms of the Creative Commons Attribution License (CC BY). The use, distribution or reproduction in other forums is permitted, provided the original author(s) and the copyright owner(s) are credited and that the original publication in this journal is cited, in accordance with accepted academic practice. No use, distribution or reproduction is permitted which does not comply with these terms. 